\title{
PENGEMBANGAN LKPD BERDASARKAN EKSPLORASI TANAMAN OBAT DI SUKU PEKAL
}

\author{
Alrevi Octavia Br. Sitorus ${ }^{1 *}$, Kasrina ${ }^{1}$, Irwandi Ansori ${ }^{1}$ \\ ${ }^{1}$ Program Studi Pendidikan Biologi, Fakultas Keguruan dan Ilmu Pendidikan, Universitas Bengkulu \\ Email: Alreviocthavia@gmail.com
}

\begin{abstract}
Abstrak
Penelitian ini bertujuan untuk (1) untuk mengetahui tumbuhan obat yang dimanfaatkan oleh masyarakat suku pekal kecamatan putri hijau kabupaten Bengkulu utara (2) untuk mengembangkan LKPD pada materi keanekaragaman hayati kelas $x$ SMA berdasarkan eksplorasi tanaman obat suku pekal kecamatan putri hijau kabupaten Bengkulu utara. Jenis penelitian ini adalah penelitian dan pengembangan dengan model Sugiyono. Hasil studi eksplorasi tanaman obat di desa pasar seblat didapatkan 36 enis tanaman dari 24 famili, family yang paling banyak digunakan adalah family Astraceae, Curcubitaceae, Lamiaceae dan Zingeberaceae. Hasil eksplorasi ini kemudian dikembangkan menjadi bahan ajar berupa LKPD yang divali dasi oleh 3 validator menunjukkan persentase keseluruhan 84,3\% dengan kriteria sangat valid. LKPD diuji keterbacaan oleh 15 peserta didik kelas x. Hasil uji kerterbacaan menunjukkan persentase $90 \%$ dengan kriteria sangat valid. Berdasarkan persentase validasi oleh ahli dan ui keterbacaan peserta didik dapat disimpulkan bahwa LKPD yang dikembangkan sangat valid dan baik untuk digunakan sebagai bahan ajar di sekolah pada sub materi keanekaragaman tingkat jenis kelas X SMA.
\end{abstract}

Kata kunci: Lembar Kerja Peserta Didik, Keanekaragaman Hayati, Tumbuhan Obat

\begin{abstract}
This study aims to (1) to find out which plants are used by the people in the small districts of North Bengkulu Regency (2) to develop LKPD on Kalas x SMA biodiversity material based on the knowledge of medicinal plants from the ethnic tribes of Putri Hijau sub-district, North Bengkulu Regency. This type of research is research and development (Research and development). The results of research on medicinal plants in the market village were 36 plants from 24 families, the most families being the family of Astraceae, Curcubitaceae, Lamiaceae and Zingeberaceae. The results of this study then became teaching material in the form of LKPD which was tie-tie by 3 validators with a total of $84.3 \%$ with very valid criteria. LKPD is read by 15 class $x$ students. The reading test results show a percentage of $90 \%$ with a very valid password. Based on fg validation by experts and the readability of the participants, it can be concluded that the developed LKPD is very valid and good for review as instructional material in schools in the submaterial of diversity in operating class $\mathrm{X}$ high school.
\end{abstract}

Keywords: Student Worksheets, Biodiversity, Medicinal Plants 


\section{PENDAHULUAN}

Pendidikan bisa membantu manusia mengangkat martabatnya melalui proses yang diselenggarakan oleh lembaga dan non lembaga. Kesuksesan penyelenggaraan pendidikan ditentukan oleh faktor alat pendidikan dan lingkungan. Upaya untuk mencapai tujuan tersebut adalah dengan mengembangkan suatu bahan ajar yang inovatif. Bahan ajar yang dapat dikembangkan salah satunya adalah Lembar Kerja peserta didik (LKPD) yang nantinya akan digunakan dalam pembelajaran, sebagai alat pendidikan (Kompri, 2015). Menurut Prastowo (2012) LKPD bisa dibuat sendiri oleh guru yang bersangkutan. Sehingga lebih menarik serta lebih kontekstual dengan situasi dan kondisi sekolah atau pun lingkungan sosial peserta didik.

Berdasarkan pengalaman peneliti dan wawancara terhadap guru biologi serta beberapa peserta didik SMAS Tenera, penggunaan LKPD hasil inovasi guru jarang sekali digunakan. Beberapa sumber belajar seperti buku paket dan LKPD yang diberikan pihak sekolah atau dari penerbit menjadi pilihan utama dalam kegiatan pembelajaran, dengan kata lain guru belum menggunakan LKPD yang didesain dengan memanfaatkan lingkungan sekitar sebagai sumber informasi pembuatan bahan ajar. Bahan ajar yang dapat dikembangkan berdasarkan lingkungan salah satunya adalah LKPD pada materi keanekaragaman hayati submateri keanekaragaman jenis. Kompetensi Dasar yang ingin dicapai yaitu, 3.2. Menganalisis berbagai tingkat keanekaragaman hayati di Indonesia beserta ancaman dan pelestariannya.

Untuk mendapatkan LKPD yang layak dan selaras dengan tujuan kompetensi dasar, maka dilakukan pengembangan LKPD dengan metode penelitian pengembangan
Sugiyono. Pemilihan metode ini dikarenakan metode ini bertujuan untuk memvalidasi dan mengembangkan produk-produk efektif seperti bahan ajar, media pembelajaran dan materi ajar yang dapat digunakan dalam pembelajaran (Sugiyono, 2008). Berdasarkan latar belakang tersebut peneliti tertarik untuk mengangkat penelitian yang berjudul "Pengembangan Lembar Kerja Peserta Didik Berdasarkan Hasil Eksplorasi Tanaman Obat Suku Pekal Desa Pasar Seblat Kecamatan Putri Hujau Kabupaten Bengkulu utara".

\section{METODE}

Jenis penelitian yang akan dilakukan adalah penelitian dan pengembangan atau Research and Development (R\&D) dengan model Sugiyono (2008). Penelitian ini dilakukan April 2018 - Sebtember 2018. Subjek penelitian dalam penelitian ini adalah peserta didik kelas X SMA TENERA. Objek penelitian dalam penelitian ini adalah LKPD sebagai bahan ajar materi keanekaragaman hayati sub materi keanekaragaman jenis.

Teknik pengumpulan data yang digunakan adalah observasi, wawancara, angket dan studi pustaka. Prosedur penelitian ini dan pengembangan menurut Sugiyono (2008) yang terdiri dari 10 langkah penelitian, namun pada penelitian ini hanya menggunakan 7 langkah dikarenakan penelitian ini terbatas pada revisi produk setelah uji keterbacaan. Adapun langkahlangkah pada penelitian ini adalah; Potensi dan masalah, Pengumpulan data, Desain Produk, Validasi Produk, Revisi Produk, Uji keterbacaan, Revisi Produk.

Data penelitian eksplorasi tumbuhan obat suku pekal dianalisis secara deskriptif. Data validasi dan uji keterbacaan LKPD yang didapatkan dianalisis menggunakan rumus : $\mathrm{P}=\frac{\sum x}{\sum x i} \times 100 \%$ (Riduwan, 2015) 
Hasil analisis data yang berupa
persentasi tersebut kemudian di
interpretasikan dengan menggunakan panduan tabel kriteria penilaian berdasarkan Ridwan (2015) yang dapat dilihat pada Tabel 1

Tabel 1. Kriteria Interpretasi Skor

\begin{tabular}{cc}
\hline Persentase & Kriteria \\
\hline $81 \%-100 \%$ & Sangat Valid / Sangat Baik \\
$61 \%-80 \%$ & Valid / Baik \\
$41 \%-60 \%$ & Cukup Valid / Cukup Baik \\
$21 \%-40 \%$ & Kurang Valid / Kurang Baik \\
\hline
\end{tabular}

\section{HASIL DAN PEMBAHASAN}

Berdasarkan hasil penelitian yang telah dilakukan tentang eksplorasi tumbuhan obat Suku Pekal di Desa Pasar Seblat Kecamatan Putri Hijau, dengan mewawancarai 4 battra diperoleh 36 jenis tanaman yang terdiri dari 24 famili yang dapat dilihat pada Tabel 2.

Tabel 2. Jenis-jenis Tumbuhan Obat yang dimanfaatkan oleh Masyarakat Suku Pekal

\begin{tabular}{|c|c|c|c|c|}
\hline No & $\begin{array}{l}\text { Famili/ Nama } \\
\text { Ilmiah } \\
\text { / Nama } \\
\text { Indonesia/ Nama } \\
\text { Lokal }\end{array}$ & $\begin{array}{c}\text { Organ } \\
\text { Tumbuhan } \\
\text { Yang } \\
\text { Dimanfaatkan }\end{array}$ & $\begin{array}{l}\text { Manfaat } \\
\text { Sebagai } \\
\text { Obat }\end{array}$ & Habitus \\
\hline 1 & Amaranhaceae & & & \\
\hline & $\begin{array}{l}\text { a. Celosia argenthea/bayam } \\
\text { kucing/bunga abang }\end{array}$ & $\begin{array}{l}\text { Bunga,batang,aka } \\
r\end{array}$ & $\begin{array}{l}\text { Gatal, bengkak, radang } \\
\text { mata }\end{array}$ & Perdu \\
\hline 2 & Acoraceae & & & \\
\hline & $\begin{array}{l}\text { a. Acorus calamus. } \\
\text { L/Dringo/Jangau }\end{array}$ & Daun, rimpang & $\begin{array}{l}\text { Hulu hati, pusing dan } \\
\text { lesu }\end{array}$ & Herba \\
\hline 3 & $\begin{array}{l}\text { Amarllidaceae } \\
\text { a.Crynum asiaticum. L/Bunga } \\
\text { Bakung/Sunu }\end{array}$ & Daun & Sakit pinggang & Herba \\
\hline 4. & $\begin{array}{l}\text { Anonaceae } \\
\text { a.Annona } \\
\quad \text { muricata/sirsak/Carikayo }\end{array}$ & Daun, buah & Hipertensi & Pohon \\
\hline 5 & $\begin{array}{l}\text { Apiaceae } \\
\text { a.Apium } \\
\text { graveolens/seledri/seledri }\end{array}$ & Daun, batang & Hipertensi & Herba \\
\hline 6 & $\begin{array}{l}\text { Apocynaceae } \\
\text { a.Parameria laevigata/kayu } \\
\text { rapet/kayu rapet }\end{array}$ & Kulit & Obat sakit mata & Semak \\
\hline 7 & Araceae & & & \\
\hline
\end{tabular}


$\begin{aligned} & \text { a. Cocos nucifera/Kelapa buah Biduran } \\ & \text { hijau/Nioh }\end{aligned}$
Asphodelaceaen

8 Asphodelaceae

a.Aloe vera L./Lidah Daun Luka bakar, jerawat Herba buaya/Lidak mayu

$9 \quad$ Asteraceae

a.Ageratum conyxoide Daun, tangkai Sakit perut, luka bakar Herba L./Babandotan/Rumput angi

b. Sonchus arvensis Bunga,daun, bata Obat radang mata, Herba sp/Lempuyang/Kunyik temu ng keseleo

10 Bromeliaceae

a.Ananas Buah Mandel Herba

11 Caricaceae
a. Carica
Daun,akar
Malaria, ginjal
Pohon papaya/pepaya/sebilo ahai

12 Crassulaceae
a. Kalanchoe
pinnata/cocor
Daun
Untuk kesuburan
Herba

13 Curcubitaceae
a. Benincasa hinsida/beligo/Pedu
b. Cucumis sativus/mentimun/lepang
Daun, bunga
Kesuburan
Semak
Buah
Hipertensi
Liana
c. Momordica
Daun charanti/pare/Piu
akar
d. Sechium edule/labu siam/jipang
Buah
tangkai, Pentakit gula
Semak

Euphorbiaceae

\section{4}
a. Jatropha curcas /Jarak/Jarak
L. Getah, daun
Masuk
angin,gatal Perdu
bibir,

15 Lamiaceae

a. Ocuim basilicum L. / Bunga selasi/Selasek

Biji, daun, batang, bunga

Panas dalam dan sendi Perdu

b. Ortoshipon spicatus/ kumis kucing/Tung'uak kucing

Daun, bunga

sakit

Sakit

pinggang, Semak

rematik

c. Plectranthus

scutellarioides/ller

Daun, tangkai, Sakit perut

Herba miana/Piung abang.
d. Ocimum xcitriodorum/kemanangi/wa ngian

akar
Daun, bunga, Meredahkan sakit Perdu batang tenggorokan, bau mulut, bau badan.

16 Menispermaceae
a. Tinospora
batang
Malaria
Semak crispa/Brotowali/ali-ali

17 Malvaceae 


\begin{tabular}{|c|c|c|c|c|}
\hline & $\begin{array}{ll}\text { a. Ceiba pentandra } \\
\text { L./Kapuk/kapas }\end{array}$ & Daun & Pening, panas & Pohon \\
\hline & $\begin{array}{l}\text { b. Hibiscus rosa- } \\
\text { sinensis/kembang } \\
\text { sepatu/ayu }\end{array}$ & Bunga & Demam, gula darah & Perdu \\
\hline 18 & Morigaceae & & & \\
\hline & $\begin{array}{l}\text { a. Moriga } \\
\text { oleiveral/kelor/Remunggai }\end{array}$ & $\begin{array}{l}\text { Daun,tangkai } \\
\text { daun. }\end{array}$ & Hipertensi, jantung & Pohon \\
\hline 19 & Musaceae & & & \\
\hline & $\begin{array}{l}\text { a. Musa } \\
\text { paradisiacal/pisang/Pisang }\end{array}$ & Batang & Panas, sakit perut & Pohon \\
\hline 20 & Myrtaceae & & & \\
\hline & $\begin{array}{l}\text { a. Psidium guajava .L/Jambu } \\
\text { biji/Jambu klutuk }\end{array}$ & Daun & Diare, malaria & Pohon \\
\hline 21 & Piperaceae & & & \\
\hline 22 & $\begin{array}{l}\text { a. Piper betle L./Sirih/Iban } \\
\text { Poaceae }\end{array}$ & Daun & obat gatal & Semak \\
\hline & $\begin{array}{l}\text { a. Imperata cilindrica/alang- } \\
\text { alang/Lalang }\end{array}$ & Akar & Panas dalam & Herba \\
\hline 23 & Rutaceae & & & \\
\hline & $\begin{array}{l}\text { a. Citrus amblycarpa/Jeruk } \\
\text { limau/Limau }\end{array}$ & Buah & $\begin{array}{l}\text { Meredam asam urat, } \\
\text { batuk, sariawan }\end{array}$ & Pohon \\
\hline 24 & Zingeberaceae & & & \\
\hline & $\begin{array}{l}\text { a. Curcuma } \\
\text { longa/kunyit/kunyik }\end{array}$ & Rimpang & Pelancar menstruasi & Herba \\
\hline & $\begin{array}{l}\text { b. Kaempfera } \\
\text { galanga/kencur/Cekoh }\end{array}$ & Rimpang & $\begin{array}{l}\text { Penambah } \\
\text { makan }\end{array}$ & Herba \\
\hline & $\begin{array}{l}\text { c. Zingiber } \\
\text { aromatic/lempuyang/melai }\end{array}$ & Rimpang & Obat sendi & Herba \\
\hline & $\begin{array}{l}\text { d. Zingiber officinale } \\
\text { rosceo/jahe/sepedah }\end{array}$ & Rimpang & Panas dalam, batuk. & Herba \\
\hline
\end{tabular}

LKPD yang telah didesain divalidasi oleh dua dosen ahli yaitu ahli bahan ajar dan ahli materi serta seorang guru biologi SMA Tenera Putri Hijau. Penilaian dilakukan berdasarkan 15 indikator yang tersusuan atas 3aspek, Kelayakan isi, kelayakan kebahasaan, kelayakan penyajian. hasil validasi dari 3 validator dapat dilihat pada Tabel 3. 
Tabel 3. Hasil Validasi LKPD

\begin{tabular}{cclccc}
\hline No & \multicolumn{1}{c}{ Penilaian } & Skor & Persentase & Kriteria \\
& $\begin{array}{c}\text { Validat } \\
\text { or }\end{array}$ & Aspek & & & Valid \\
\hline 1 & Ahli & Kelayakan Isi & 21 & $81,6 \%$ & \\
& Bahan & Kelayakan Kebahasaan & 8 & & Sangat Valid \\
& Ajar & Kelayakan penyajian & 20 & & \\
& Ahli & Kelayakan Materi & 19 & $83,3 \%$ & Sangat Valid \\
& Materi & Kelayakan Bahasa & 8 & & \\
& & Kelayakan Penyajian & 23 & & \\
& Guru & Kelayakan Materi & 24 & $90,0 \%$ & \\
& Biologi & Kelayakan Bahasa & 8 & & Sangat valid \\
& SMA & Kelayakan Penyajian & 22 & &
\end{tabular}

Setelah dilakukan validasi, maka dilakukan Uji Keterbacaan untuk mengetahui tanggapan peserta didik terhadap LKPD hasil pengembangan. Dari uji keterbacaan diperoleh beberapa saran antara lain kualitas cetakan gambar lebih diperjelas lagi, pemilihan warna pada LKPD dapat dibuat lebih menarik, dan menambahkan banyak gambar agar lebih memicu minat baca, sesui dengan Eanes (1997) ada beberapa upaya yang dapat dilakukan untuk meningkatkan minat baca salah satunya yaitu memberi bahan bacaan yang dilengkapi dengan gambar dan ilustrasi yang menarik. Uji ini dijadikan tolak ukur kualitas bahan ajar yang telah dikembangkan. Hasil Uji Keterbacaan dapat dilihat pada Tabel 4.

Tabel 4. Hasil Uji Keterbacaan

\begin{tabular}{|c|c|c|c|c|}
\hline No & Responden & Skor & Persentase & Kriteria \\
\hline 1 & Afr & 9 & $90 \%$ & Sangat Baik \\
\hline 2 & Ali & 9 & $90 \%$ & Sangat Baik \\
\hline 3 & Ang & 8 & $80 \%$ & Sangat Baik \\
\hline 4 & cndr & 10 & $100 \%$ & Sangat Baik \\
\hline 5 & $\mathrm{Dn}$ & 9 & $90 \%$ & Sangat Baik \\
\hline 6 & Eme & 10 & $100 \%$ & Sangat Baik \\
\hline 7 & hend & 9 & $90 \%$ & Sangat Baik \\
\hline 8 & jnt & 9 & $90 \%$ & Sangat Baik \\
\hline 9 & $\mathrm{Jmr}$ & 10 & $100 \%$ & Sangat Baik \\
\hline 10 & Kvn & 7 & $70 \%$ & Baik \\
\hline 11 & Ist & 9 & $90 \%$ & Sangat Baik \\
\hline 12 & Oes & 9 & $90 \%$ & Sangat Baik \\
\hline 13 & slv & 8 & $80 \%$ & Sangat Baik \\
\hline
\end{tabular}




\begin{tabular}{rrrrr}
\hline 14 & tes & 8 & $80 \%$ & Sangat Baik \\
15 & tr & 9 & $90 \%$ & $\begin{array}{l}\text { Sangat Baik } \\
\text { Sangat Baik }\end{array}$ \\
\hline
\end{tabular}

Tumbuhan obat di desa Pasar Seblat ditemukan sebanyak 36 spesies dalam 24 famili. Informasi mengenai tumbuhan berkhasiat obat dan cara pengolahannya diperoleh battra dari orangtua, kakek atau nenek yang diwariskan secara turuntemurun. Jika dilihat dari beberapa literatur seperti buku Tanaman Obat (Pratama, 2007) dan Tanaman Obat (Redaksi Agro Media, 2007) yang dijadikan panduan untuk identifikasi, sebenarnya tumbuhan yang ada disekitar Desa Pasar Seblat memiliki lebih banyak tumbuhan yang bisa dijadikan obat, namun masyarakat yang mempunyai pengetahuan tentang tumbuhan obat baru mengenal dan memanfaatkan 36 jenis tumbuhan obat.

Famili tumbuhan obat yang dimanfaatkan yaitu sebanyak 36 jenis dari 24 famili, dari 24 famili tersebut yang lebih banyak dimanfaatkan oleh Suku Pekal desa Pasar Seblat adalah Famili Cucurbitaceae berjumlah 4 spesies, lamiaceae berjumlah 4 spesies dan Zingeberaceae berjumlah 4 spesies. Tanaman obat yang termasuk Famili Curcubitaceae yakni Benincasa hinsida(beligo/Pedu), Cucumis sativus (mentimun/lepang), Momordica charanti (pare/Piu), Sechium edule (Labu siam/jipang). Tanaman obat yang termasuk Tanaman obat yang termasuk Lamiaceae yaitu Ocuim basilicum L. (Bunga selasi/Selasek), Ortoshipon spicatus (kumis kucing/Tung'uak kucing), Plectranthus scutellarioides (Iler miana/Piung abang), Ocimum xcitriodoru (kemanangi). Famili Zingiberaceae adalah Alpinia galanga $L$.
(Lengkuas), Curcuma domestica (Kunyit), Kaempferia galanga L. (Kencur), Zingiber officinale (Jahe).

Banyaknya pemanfaaatan suku Zingeberaceae seiring pada penelitian tumbuhan obat sebelumnya yang telah dilakukan oleh (Tiara 2015) tentang studi etnobotani jenis-jenis tumbuhan obat oleh masyarakat Talang Jawi Kecamatan Padang Guci Kota Kaur yang menemukan 6 jenis suku Zingeberaceae. Adapun penelitian yang dilakukan oleh (Fahlefi 2013) tentang Etnobotani Pemanfaatan Tumbuhan Obat Oleh Masyarakat di Kecamatan Wonotirto Kabupaten Blitar, paling banyak menggunakan suku Zingeberaceae sebanyak 7 jenis.

Berdasarkan eksplorasiyang didapatkan selanjutnya dikembangkan suatu bahan ajar yaitu Lembar kegiatan Peserta Didik (LKPD). LKPD merupakan suatu bahan ajar cetak berupa lembar-lembar kertas yang berisi materi, ringkasan dan petunjukpetunjuk pelaksanaan tugas pembelajaran yang harus dikerjakan oleh peserta didik, yang mengacu pada kompetensi dasar yang harus dicapai (Prastowo, 2011).

LKPD yang dikembangkan pada penelitian ini dibuat berdasarkan potensi lingkungan sekitar peserta didik dengan kata lain memanfaatkan lingkungan sekitar sebagai sumber informasi pembuatan bahan ajar. Hal ini sesuai dengan pendapat Uno dan Mohamad (2014) penggunaan lingkungan sebagai sumber belajar memiliki kelebihan antara lain peserta didik dibawa langsung ke dalam dunia yang konkret tentang konsep 
pembelajaran, sehingga peserta didik tidak hanya mengkhayalkan materi. Pendapat ini juga didukung oleh Zukmadini, dkk (2018) yang menyatakan bahwa pengembangan bahan ajar berbasis kearifan lokal dalam penggunaan tanaman obat, memiliki potensi untuk membantu para guru dalam mencapai tujuan pembelajaran sesuai dengan tuntutan kurikulum dan standar Kompetensi. Ini karena materi yang disajikan memunculkan masalah pemanfaatan keanekaragaman hayati untuk suku komunitas di area tertentu tanpa menghilangkan tuntutan kurikulum dan tujuan pembelajaran yang telah dirumuskan oleh guru.

Pengembangan LKPD pada penelitian ini juga menampilkan ringkasan materi yang berbeda. Materi yang disajikan berisi tentang penjelasan mengenai Suku Pekal serta disajikan hasil riset penelitian tentang eksplorasi tumbuhan obat yang dimanfaatkan oleh suku Pekal sebagai informasi baru yang disajikan. Selain itu, pada LKPD ini tugas yang akan dikerjakan oleh peserta didik tidak hanya terbatas pada pengamatan morfologi saja, tetapi juga terdapat pertanyaan analisis mengenai kenaekaragaman tanaman obat dan manfaat tanaman obat.

LKPD yang telah disusun selanjutnya akan divalidasi oleh para ahli. Berdasarkan hasil validasi, LKPD dinilai telah memenuhi kriteria sangat valid dengan presentase hasil angket sebesar $84,9 \%$. Hasil validasi ini membuktikan bahwa bahan ajar yang dibuat telah memenuhi kriteria-kriteria sebagai bahan ajar yang telah sesuai dengan sasaran yang akan dicapai peserta didik dalam hal ini $\mathrm{KI}$ dan KD, sudah mengacu kepada kaidah bahasa Indonesia yang baik dan benar, konsep materi yang disajikan sistematik, menarik dan mampu mendorong peserta didik untuk aktif, dan memenuhi syarat kegrafikan dalam segi tampilan yang menarik, serta mudah untuk dibaca dan digunakan (Muljono, 2007).

LKPD yang telah divalidasi selanjutnya diuji keterbacaan oleh 15 orang peserta didik kelas X IPA di SMA Tenera. Terdapat komponen yang dinilai oleh peserta didik yaitu aspek materi, aspek bahasa dan aspek penyajian,. Secara keseluruhan LKPD telah memenuhi kriteria sangat baik dengan presentase hasil angket sebesar $88,6 \%$.

Uji keterbacaan peserta didik dilakukan untuk mengetahui pendapat peserta didik terkait bahan ajar yang dikembangkan, hal ini sesuai dengan Tessmer dalam Dewi (2012) bahwa kriteria kualitas bahan pembelajaran dapat dikaitkan dengan kesesuaian bahan pembelajaran dengan karakteristik peserta didik serta kemenarikan bahan ajar tersebut bagi peserta didik.

Desain LKPD hasil pengembangan yang telah divalidasi meliputi 1) Cover, 2) judul, 3) Tujuan pembelajaran, 4) Konsep, 5) Alat dan bahan 6) Cara kerja, 7) Tabel pengamatan, 8) Pertanyaan dan 9) Kesimpulan. Cover LKPD didesain semenarik mungkin dengan menampilkan beberapa foto tumbuhan obat suku Pekal. Selanjutnya terdapat tujuan pembelajaran yang dikembangkan dari KD. Selajutnya disajikan materi/konsep keanekaragaman dengan memperkenalkan terlebih dahulu tentang suku Pekal dan spesies-spesies tumbuhan obat yang dimanfaatkan oleh suku Pekal.

Halaman berikutnya terdapat prosedur kerja yang terdiri dari alat dan bahan yang digunakan beserta cara kerjanya. Kemudian di halaman selanjutnya terdapat tabel pengamatan yang harus diisi oleh peserta didik dan dilanjutkan dengan pertanyaan sebanyak 4 butir pertanyaan yang dikembangkan dari tujuan pembelajaran. Pada halaman terakhir 
terdapat bagian kesimpulan, yang harus diisi oleh peserta didik.

\section{PENUTUP}

Kesimpulan

1.Tumbuhan obat yang dimanfaatkan oleh masyarakat suku pekal desa pasar seblat Kecamatan Putri Hijau Kabupaten Bengkulu Utara terdapat 36 jenis tumbuhan obat yang tergolongdalam 24 famili dan yang paling banyak digunakan sebagai obat adalah famlili Astraceae, Cucurbitaceae, lamiaceae dan Zingeberaceae.

2. Desain LKPD dikembangkan berbasis lingkungan. Adapun sistematika desain LKPD yang dikembangkan adalah cover, judul, tujuan pembelajaran, konsep, alat dan bahan, cara kerja, tabel pengamatan, pertanyaan, kesimpulan. LKPD dinilai sangat valid berdasarkan hasil keseluruhan $84,3 \%$ dan uji keterbacaan oleh peserta didik dengan presentase keseluruhan $90 \%$ yang berarti LKPD sudah dinilai sangat baik.

Saran

1. Untuk peneliti selanjutnya diharapkan agar melakukan penelitian di daerah lain tentang eksplorasi tumbuhan obat apa saja yang dimanfaatkan supaya memperkaya pengetahuan jenis-jenis tumbuhan obat yang belum terdata diskripsi sebelumnya sehingga terdapat data baru tentang jenis tumbuhan obat.

2. Untuk peneliti selanjutnya diharapkan agar tidak hanya berfokus pada bahan ajar cetak namun dikembangakan dalam bentuk multimedia interaktif atau bahkan dikembangakan secara online, sehingga semua peserta didik lebih semangat dan lebih mudah belajar, namun semuanya juga tidak lepas dari pertimbangan karakteristik dan kebutuhan peserta diidik, sehingga dihasilkan memang tepat guna dan sasarannya.

3. Bagi peneliti, perlu adanya pemilihan narasumber yang tepat agar info yang didapat lebih maksimal, karena dengan kurang terbukanya narasumber maka penelitian akan susah dalam hal pengumpulan data.

\section{DAFTAR PUSTAKA}

Agromedia, 2007. Buku Pintar Tumbuhan Obat. Jakarta: PT. Agromedia Pustaka.

Dewi, Ghea P. F. 2012. Pengembangan Game Edukasi Pengenalan Nama Hewan Dalam Bahasa Inggris Sebagai Media Pembelajaran Siswa SD Berbasis Macromedia Flash. Yogyakarta : Universitas Negeri Yogyakarta. (http://eprint.uny.sc.id)

Eanes, R. 1997. Content area literacy: teaching for today and tomorrow. Bon: Dermar publishing company.

Fahlefi, M. 2013. Etnobotani Pemanfaatan Tumbuhan Obat Oleh Masyarakat Di Kecamatan Wontirto Kabupaten Blitar. Malang : Universitas Islam Negri Maulana Malik Ibrahim Malang.

Kompri, 2015. Managemen Pendidikan, Komponen-Komponen Elementer Kemajuan Sekolah. Yogyakarta : Arruzzmedia.

Muljono, Pudji. 2007. Kegiatan Penilaian Buku Teks Pelajaran Pendidikan 
Dasar dan Menengah Vol II No 1. http://www.bsnp-indonesia.org

Prastowo, Andi. 2011. Panduan Kreatif Membuat Bahan Ajar Inovatif. Yogyakarta : Diva Press

Permana, H. 2007. Tumbuhan Obat Tradisional. Bandung: TITIAN ILMU.

Riduwan. 2015. Skala Pengukuran Variabelvariabel Penelitian. Bandung : ALFABETA

Sugiyono. 2008. Metode Penelitian Pendidikan. Bandung : Alfabeta

Uno, H.B., N. Mohamad, 2014. Belajar dengan Pendekatan PAILKEM. Jakarta: Bumi Aksara

Zukmadini, Alif Yanuar., Jumiarni, Dewi., Kasrina. 2018. Developing Antimicrobial Medicinal Plants Pocketbook Based on Local Wisdom of Muko-Muko and Serawai Ethnics.
Jurnal Pendidikan Biologi Indonesia.

4

(2):

95-104.

http://ejournal.umm.ac.id/index.p hp/jpbi/article/view/5436.

Tiara N. 2015. Pengembangan LKS Berdasarkan Inventaris Tumbuhan Obat Yang Dimanfaatkan Oleh Masyarakat Talang Jawi II Kec. Padang Guci Hilir Kab. Kaur Dan Implementasinya Pada Pembelajaran Biologi Di SMA 4 Kaur. Bengkulu : Universitas Bengkulu 